\title{
A construção da diferença sexual na medicina
}

\author{
The construction of sexual difference in medicine
}

Fabíola Rohden 1

\footnotetext{
1 Programa de Estudos e Pesquisas em Gênero, Sexualidade e Saúde, Centro Latino-Americano em Sexualidade e Direitos Humanos, Instituto de Medicina Social, Universidade do Estado do Rio de Janeiro. Rua São Francisco Xavier 524, 7o Andar, Blocos D e E, Rio de Janeiro, RJ 20559-900, Brasil. fabiola@ims.uerj.br
}

\begin{abstract}
This article discusses the work of some key players in the current debate on the construction of the notion of sexual difference in modernity, taking as the focus of analysis and illustration the theses submitted at the School of Medicine in Rio de Janeiro, Brazil, during the $19^{\text {th }}$ century. The objective is to confront the argument that the difference between the sexes comes to be taken for granted and considered immutable by science. This emphasis on a natural difference between the sexes is related to transformations that occurred beginning in the late $18^{\text {th }}$ century (growing industrialization and urbanization, more extensive participation by women in the labor market, the emergence of women's rights movements) that required changes in the established gender relations. Still, it is precisely through the attempts to prove that the difference was natural that one perceives how unstable and threatening it was. Interventions such as women's education and labor market participation were capable of altering and even "subverting" the difference. Thus, "natural" was not synonymous with definitive or guaranteed.
\end{abstract}

Key words Gender; Sexuality; History of Medicine

Resumo O artigo discute o trabalho de alguns autores fundamentais no debate atual acerca da construção da noção de diferença sexual na modernidade, tomando como foco de análise e de ilustração as teses apresentadas à Faculdade de Medicina do Rio de Janeiro durante o século XIX. O objetivo é problematizar o argumento de que a diferença entre os sexos passa a ser considerada como natural e imutável pela ciência. Essa ênfase na naturalidade estaria relacionada com as transformações ocorridas a partir do fim do século XVIII (crescente industrialização e urbanização, entrada mais efetiva das mulheres no mercado de trabalho, surgimento de movimentos de reivindicação de direitos) que requeriam mudanças nas relações de gênero estabelecidas. Contudo, nota-se que é exatamente por meio das tentativas de provar que a diferença era natural que se pode perceber o quanto ela era instável e ameaçadora. Intervenções como a educação e o trabalho da mulher poderiam alterar e mesmo "perverter" a diferença. Ser natural, portanto, não significava ser definitivo ou estar garantido.

Palavras-chave Gênero; Sexualidade; História da Medicina 
"Fundida em um novo molde a mulher entra no torneio da vida para ser dada em holocausto ao papel sublime da maternidade que a constitui a abóbada do edifício familiar; é nesta nova fase chamada por Buffon, de primavera da vida, de estação dos prazeres, que ela exibe o seu temperamento particular, destacando-se do sexo contrário por um fluxo intermitente denominado mênstruos, catamênios, luas, ordinárias e mais acertadamente regras, se bem que ainda existam expressões outras não merecedoras de referência.

Essa tradução externa da aptidão reprodutora do sexo feminino, esse atributo significativo da puberdade metamorfoseia a mulher, física e moralmente, pois com ele se inicia a diferenciação dos dois seres da escala superior da organização humana, até então nascidos, crescidos $e$ evoluídos sob o influxo uniforme e imutável das mesmas leis da natureza" (Barbosa, 1891:3-4).

A passagem acima foi transcrita da obra Desordens Catameniais, tese apresentada à Faculdade de Medicina do Rio de Janeiro em 1891, por Pedro L. Barbosa. Embora o tema pareça destinado a um recorte bem objetivo, as pretensões explicativas do autor não eram poucas. Para Barbosa, assim como para muitos de seus colegas, tratar de eventos característicos da vida da mulher implicava não apenas o descrever as doenças pertinentes mas também em discutir o seu papel na sociedade. A menstruação, por exemplo, é objeto central do argumento, extremamente presente no período, de que a vida da mulher está fortemente associada à reprodução, característica que sintetizaria a diferença entre os sexos. Representa o demarcador que separa um período em que as diferenças entre meninos e meninas eram inexistentes ou apagadas, para um outro em que os dois sexos passam a se distinguir radicalmente.

Neste artigo, pretendo discutir como essa ênfase da medicina na distinção entre homens e mulheres está articulada com questões mais gerais relativas ao contexto social em cena, ao desenvolvimento científico e, mais particularmente, à importância da discussão em torno da dicotomia natureza/cultura para a sociedade ocidental moderna. Gostaria de destacar que, além da preeminência dada à diferença entre os sexos, uma outra característica marca profundamente a produção científica do século XIX. Trata-se da noção de instabilidade, traduzida, por exemplo, na idéia de que a puberdade é um momento que precisa ser muito bem administrado para que o processo de diferenciação se realize a contento.
Analisando textos médicos do século XIX, podemos identificar uma complexa relação entre aquilo que é definido como as marcas dadas pela natureza e o que é apresentado como as intervenções da ordem da cultura. A natureza teria definido o que distingue homens e mulheres. Mas as influências do meio podem intervir no processo de estabelecimento e cristalização das diferenças.

Esse tema tem impulsionado uma série de trabalhos nas últimas décadas. Um deles, em particular, tem ganho um maior destaque pelo pioneirismo em uma abordagem que já se tornou uma referência. Trata-se do livro de T. Laqueur (2001), intitulado Inventando o Sexo: Corpo e Gênero dos Gregos a Freud. Seguindo os passos de Foucault, Laqueur tenta identificar as grandes transformações que ocorreram no decorrer da história da sociedade ocidental no que diz respeito às concepções de sexo e gênero e, portanto, também de natureza e cultura.

Laqueur $(1987,2001)$ argumenta que as diferenças entre os sexos ou a própria idéia de dois sexos biológicos distintos é uma concepção que pode ser historicamente contextualizada. Assim como outros autores, afirma que a partir do século XVIII passa-se a considerar a existência de um modelo de dois sexos, contrariamente à percepção herdada dos gregos de que haveria apenas um sexo biológico, enquanto o gênero se apresentaria pelo menos em duas possibilidades. Neste modelo antigo, de um sexo, homem e mulher não seriam definidos por uma diferença intrínseca em termos de natureza, de biologia, de dois corpos distintos, mas, apenas em termos de um grau de perfeição. Dependendo da quantidade de calor atribuída à cada corpo, ele se moldaria em termos mais ou menos perfeitos, em um corpo de homem quando o calor foi suficiente para externalizar os órgãos reprodutivos, ou em um corpo de mulher quando foi insuficiente e os órgãos permaneceram internos. As diferenças seriam de grau, compondo uma hierarquia vertical entre os gêneros. Os órgãos reprodutivos seriam vistos como iguais em essência e reduzidos ao padrão masculino. Ou seja, ambos, homens e mulheres, seriam dotados de pênis e testículos, por exemplo. A única diferença é que na mulher esses órgãos não foram externalizados. Haveria, então, um só corpo, uma só carne, para a qual se atribuem distintas marcas sociais.

A partir do Renascimento pode-se perceber um enfraquecimento desse modelo antigo em prol do surgimento de um modelo que en- 
fatiza a existência de dois sexos distintos. A partir de então é possível e necessário falar de uma biologia da incomensurabilidade. Em contraste com o esquema hierárquico anterior, o novo dimorfismo institui uma diferença radical entre homens e mulheres. Segundo Laqueur (2001), as causas dessa transformação não se restringiriam a meras mudanças provocadas pelos progressos da ciência, mas têm a ver com um contexto mais amplo de transformações no qual se destacam dois focos fundamentais: uma mudança epistemológica e uma mudança política.

A primeira se dá a partir do contexto da revolução científica, propagada por Bacon, Descartes, o mecanicismo, o empiricismo, a síntese newtoniana, que tinha solapado o modo galênico de compreender o corpo em relação ao cosmos e abandonado o isomorfismo entre homens e mulheres. Engloba tanto a instituição de algumas dicotomias básicas, como fato e ficção, ciência e religião, razão e credulidade, corpo e espírito, verdade e falsidade, sexo biológico e gênero teatral, quanto o rompimento com a episteme da "grande cadeia do ser". A associação infindável de signos, entre corpo e cosmos, dá lugar à redução a um plano único, o plano da natureza, onde a explicação reducionista e o sexo como fato físico são viáveis. Essas mudanças só foram possíveis em conjunção com um novo contexto político, especialmente centrado nas divisões entre esfera pública e esfera privada, homens e mulheres, partidários e contrapartidários da autonomização feminina. É recorrendo aos pais fundadores da teoria política que Laqueur (2001) vai reforçar o seu argumento. Afirma que para Hobbes, assim como para Locke, não há base na natureza, na lei divina, ou na ordem cósmica transcendente para justificar autoridades específicas como a do rei sobre o súdito, do senhor sobre o escravo e, possivelmente, do homem sobre a mulher. Contudo, para os mesmos autores, os homens continuam sendo os chefes das famílias assim como também os chefes das nações. Só os homens, e não as mulheres, fazem o contrato social.

A fundação desta diferença estaria não em algo transcendental mas no fato da diferença sexual e suas implicações utilitaristas, ou seja, a constatada força superior dos homens e a freqüente incapacidade das mulheres em decorrência de suas funções reprodutivas. O corpo, que para a visão de mundo centrada na "grande cadeia do ser" era o signo, passa agora a ser o fundamento da sociedade civil. É utilizado por diferentes visões para expressar as novas demandas surgidas em novos contextos soci- ais, econômicos, políticos, culturais e eróticos. As diferenças que antes eram expressas em termos de gênero, agora são evidenciadas pelo sexo, pela biologia. E a ciência torna-se cada vez mais fundamental na medida em que passa a fornecer argumentos para o debate ideológico.

As diferenças biológicas diagnosticadas pelos cientistas passam a oferecer a base para que pensadores sociais dissertem sobre as supostas diferenças inatas entre homens e mulheres e a conseqüente necessidade de diferenciações sociais. A natureza já tinha se encarregado de postular a divisão e caberia à sociedade respeitá-la e promover um comportamento adequado. Para os iluministas, a mulher era incapaz de assumir responsabilidades cívicas. $\mathrm{O}$ contrato social, então, só era possível entre homens. A biologia da incomensurabilidade fornecia um modo de explicar as diferenças sociais, já que na própria natureza homens e mulheres eram diferentes, e mais do que isto, as mulheres eram naturalmente inferiores. A ciência, e em particular a medicina, se esmerava em acrescentar novos e intrigantes detalhes que provavam a intransponibilidade da diferença, que no século XIX já seria considerada inquestionável. Instaura-se um modelo caracterizado pelo dimorfismo radical, pela divergência biológica, no qual todas as partes do corpo apresentariam diferenças radicais não apenas no que era mais aparente, mas mesmo em elementos microscópicos. Segundo Laqueur, a diferença sexual não era percebida como uma variação de grau mas de espécie e parecia solidamente baseada na natureza. Além disso, acrescenta que: "a visão dominante desde o século XVIII, embora de forma alguma universal, era que há dois sexos estáveis, incomensuráveis e opostos, e que a vida política, econômica e cultural dos homens e das mulheres, seus papéis no gênero, são de certa forma baseados nesses 'fatos'. A biologia - o corpo estável, não histórico e sexuado - é compreendida como o fundamento epistêmico das afirmações consagradas sobre a ordem social" (Laqueur, 2001:18).

Como podemos ver, Laqueur (2001) atesta com veemência o predomínio do modelo da diferença sexual a partir do final do século XVIII. Uma série de outros autores (Bullough \& Voght, 1973; Gay, 1984; Jordanova, 1989; Kent, 1990; Martensen, 1998; Matus, 1995; Moscucci, 1996; Russet, 1995; Schiebinger, 1987; Steinbrügge, 1995; Vertinsky, 1990) têm ajudado a compor esse panorama estudando não só a ciência ou a medicina, mas outras fontes importantes de formação de opinião e reflexão sobre a sociedade, como é o caso da literatura. Para além de 
uma concordância mais geral em torno da hipótese do interesse pela diferenciação entre os sexos calcada na biologia, há algumas ponderações importantes a acrescentar. Interessam aqui principalmente os argumentos que tratam não apenas da delimitação da diferença, mas também do seu caráter instável.

O trabalho de Jordanova (1989) é com certeza uma referência fundamental nesse debate. A autora, estudando as imagens relativas ao gênero na ciência e medicina do século XVIII ao século XX, mostra como há um incessante anseio na história de nossa sociedade por clarificar áreas consideradas problemáticas ou instáveis nas nossas representações, como seriam os domínios da natureza, cultura e gênero. A preeminência e a constância de dicotomias ou de características oposicionais representariam tentativas de dar conta dessa necessidade. Dicotomias como homem/mulher ou natureza/cultura, mas também campo/cidade, matéria/espírito, corpo/mente, público/privado, etc., têm uma história particular, relacionam-se entre si e se transformam com o passar do tempo, demonstrando que não se trata de simples hierarquias lineares ou estáticas. Aliás, é exatamente a possibilidade dos limites tornarem-se vagos ou fluidos que provoca maior interesse, na ciência especialmente. É como se a manutenção da ordem social dependesse dessas tentativas de clarificação. Os debates sobre sexo e papéis sexuais, por exemplo, especialmente no século XIX, se concentram nos modos por meio dos quais as fronteiras sexuais podem ser borradas. Naquele momento, os médicos direcionavam suas atenções para as possibilidades de feminização do homem, representada pela homossexualidade, e de masculinização da mulher, que seria o resultado do excesso de trabalho físico e mental. Parecia então evidente que as influências do meio poderiam intervir na operação de distinção entre os sexos (Jordanova, 1989).

Jordanova (1989) chama a atenção para o fato de que, muitas vezes, a distinção entre homens e mulheres estava centrada muito mais em graus diferenciados de potencialidades humanas do que em uma diferença radical. Recorre ao exemplo da distinção psicológica entre homens e mulheres. No século XVIII, imaginava-se que em cada indivíduo aconteceria uma luta interna entre os elementos considerados masculinos (como a razão e a inteligência) e aqueles percebidos como femininos (como a paixão e a emoção). Em termos de estereótipos, os homens seriam sérios e pensativos e as mulheres, frívolas e emotivas. Mas não havia uma total divisão das propriedades mentais por sexo e sim um contínuo. Já no século XIX, a divisão psicológica entre os sexos torna-se rígida e chega-se mesmo a duvidar da presença da razão nas mulheres, que passam cada vez mais a ser associadas a características como a paixão e a emoção. A partir de então, a oposição entre os pólos começa a ser entendida como mais rígida e menos flexível.

$\mathrm{O}$ que parece mais interessante no argumento da autora é o fato de que as relações entre os pares de oposição implicavam as construções complexas. Considerando que valores variados podem ser associados a indivíduos, a pares ou mesmo a conjuntos de dicotomias, não era possível pensar em uma única e contínua escala. Contudo, o problema mais significativo era o perigo da indistinção ou do ultrapassamento das fronteiras: "freqüentemente era precisamente o grau de indistinção entre os dois lados que era o mais notado. Por exemplo, debates sobre sexo e papéis sexuais, especialmente durante o século XIX, vinculavam-se às maneiras pelas quais as fronteiras sexuais se tornavam borradas. Era como se a manutenção da ordem social dependesse da clarificação de certas distinções cruciais cujos significados simbólicos disseminavam-se para bem além do seu contexto explícito" (Jordanova, 1989:22; tradução da autora).

Além disso, admitir as influências do meio sobre a humanidade era uma concepção bastante vigorosa na época. Todas as coisas vivas e o ambiente estavam sempre em contínua interação e cada um poderia mudar o outro. As diferenças sexuais, assim como a anatomia e a fisiologia, também eram passíveis de sofrer transformações. Se, por um lado, admitia-se que as diferenças estavam enraizadas na natureza, em virtude da relação com as características físicas de cada sexo, por outro, eram percebidas como mutáveis. Como os aspectos fisiológicos, mentais e sociais do ser humano eram percebidos como em profunda interação, o gênero também sofria das influências dos costumes e hábitos da vida cotidiana como dieta, exercícios, ocupação (Jordanova, 1989).

$\mathrm{O}$ argumento da permeabilidade dos corpos, dos sexos e dos gêneros às influências externas é aprofundado pelo trabalho de Matus (1995). Estudando as representações sobre sexualidade e maternidade na Inglaterra Vitoriana, a autora enfatiza que, embora a diferença sexual seja entendida como natural ou condição biológica pré-dada, ela é ao mesmo tempo concebida como instável e precária, adquirida na puberdade mais do que manifestada no nascimento. Está se falando de uma concepção de transitividade sexual, ou seja, de um conti- 
nuum entre os dois sexos mais do que de uma divisão radical entre opostos incomensuráveis. Esta idéia abre espaço para uma maior atenção ao que as condições sociais poderiam fazer com as provisões que a natureza fornecera. Ao mesmo tempo em que se preservava a noção de sexualidade como um mandato natural ou biológico, permitia pensar que a cultura poderia transformá-la, refinando-a ou desestabilizando-a. Isso requereria, portanto, um cuidadoso monitoramento e avaliação das diferenças culturais. Segundo Matus (1995:10; tradução da autora), "a natureza havia feito provisões para a sexualidade humana, mas a cultura estava livre para perverter, distorcer ou conspurcar os dons naturais".

A partir daí, Matus (1995) afirma que os debates em torno da diferença sexual colocavam em cena distintas representações sobre sexo, natureza e cultura que explicitavam interesses diferenciados. Estas representações, nos textos vitorianos, não seriam homogêneas ou consistentes, mas múltiplas e contraditórias, mesmo dentro de grupos específicos como o de médicos homens ou de mulheres escritoras, por exemplo. Nesse sentido, a perspectiva de Foucault da sexualidade como uma construção cultural e um processo complexo e instável, na qual estão em jogo uma multiplicidade de elementos discursivos, é de grande valia. Para Matus, a noção de instabilidade é fundamental, tanto no sentido de que o discurso biomédico elabora uma noção de corpo instável, quanto com relação ao fato de que as próprias representações constituem um "corpo instável” de discurso. Esse enfoque leva a autora a destacar a noção de propensão natural. O termo propensão aponta para a idéia de atividade, para a possibilidade de mudança ou movimento, mas implica também a noção de direcionamento. As propensões fundamentam-se em forças naturais mas são também instáveis e mutáveis.

Ao mesmo tempo em que a diferença sexual ganha um enorme destaque, preocupa-se com a sua instabilidade. O sexo aparece como um processo dinâmico que responde ao ambiente e aos hábitos e depende de um corpo permeável e mutável. Se por um lado era preciso legitimar a radicalidade da diferença sexual entre homens e mulheres, por outro, as teorias da fluidez sexual eram úteis na formulação de idéias sobre as diferenças entre mulheres de diferentes classes ou culturas, por exemplo. Haveria uma essência comum a todas as mulheres, mas também diferenças entre elas. A nítida distinção entre os sexos constituía um imperativo da cultura vitoriana e as representações médicas eram importantes elementos que participavam na elaboração dessa distinção. Porém, sexo e sexualidade eram também categorias ambíguas dentro deste discurso. A noção de diferença sexual implicava a consideração de semelhança e continuidade, dos imperativos da natureza e da cultura. Mais do que grandes certezas, muitas dúvidas caracterizavam o pensamento sobre as diferenças entre os sexos (Matus, 1995).

Matus (1995), discutindo com o trabalho de Laqueur (2001), argumenta que o modelo binário da diferença sexual teria um papel de extrema importância na conformação da ideologia vitoriana que precisava representar a diferença como natural, corporal, anatômica. Entretanto, embora a biologia da diferença servisse à hegemonia da classe média vitoriana, justificando formas de organização social dependentes da definição da mulher como essencialmente diferente, também tinha usos políticos ambivalentes. As idéias sobre a diferença, assim como o uso ideológico do corpo sexuado eram complexos e diversos, mais que monolíticos ou misóginos. Apesar da força dada à diferença, também havia lugar para uma similaridade entre os sexos. Laqueur, em virtude de uma preocupação central com o poder da diferenciação sexual, teria dado pouca atenção às idéias em torno da similaridade. Para Matus, o problema da diferença era pensado muito mais em termos de grau do que de espécie, apesar da crescente insistência na diferença sexual.

A ênfase na diferenciação poderia significar que as ambigüidades sobre a categorização sexual eram omitidas nas apropriações culturais do discurso médico porque seriam irrelevantes para fins políticos ou econômicos. Mas, tal conclusão pressuporia que a relação entre o discurso médico e a cultura em geral seria simplesmente de causa e efeito. A cultura se apropriaria somente do que lhe seria útil. Na opinião da autora, o jogo entre as descobertas científicas e os imperativos culturais não é de mão única. O fato de que as idéias sobre uma aproximação entre os sexos também persistiam no discurso biomédico, sugere que elas também correspondem a necessidades ideológicas. Segundo Matus (1995:24; tradução da autora), apesar de potencialmente perturbadoras, “as questões sobre sexualidade ambígua abrem a porta para o escrutínio das relações entre natureza e cultura e estruturam os debates em torno do determinismo biológico e das influências do ambiente".

As influências do meio são um tema recorrente no pensamento médico do século XIX. Aquilo que a natureza havia fornecido poderia 
ser modificado pelo ambiente, a nutrição ou a vida social. Já que mesmo o corpo poderia ser moldado, a cultura, o meio, precisariam ser regulados e controlados. Embora a natureza tivesse providenciado a diferença entre homens e mulheres, sua clara definição durante a vida poderia sofrer ameaças. Por isso insiste-se tanto na necessidade de um monitoramento, que atinge de maneira especial a mulher (Matus, 1995). Seu corpo, na medida em que era visto acima de tudo como o corpo reprodutivo, demandava uma atenção especial. Da boa administração do desenvolvimento corporal e da capacidade reprodutiva das mulheres dependeria o desenvolvimento de cada sociedade. Em uma época em que se costumava comparar o grau de civilização dos povos pelo cuidado dedicado à obstetrícia, qualquer possível influência negativa ao potencial reprodutivo era percebida como uma ameaça, tal como era o caso da educação feminina (Matus, 1995).

III

Os argumentos em torno de um cuidado maior na administração do processo que leva os seres do sexo feminino a atingir a perfectibilidade têm uma outra raiz importante. Trata-se da noção de que as mulheres seriam mais vulneráveis do que os homens às influências externas. Sendo assim, se em um plano temos a afirmação da instabilidade da diferença sexual e a necessidade de seu governo, em outro, identificamos a crença em uma instabilidade muito maior nas mulheres, o que implicaria o controle muito mais atento no seu caso.

As mulheres pareciam mais sujeitas a todo tipo de influências, na medida em que se concebia que eram mais frágeis e vulneráveis tanto física quanto moral e intelectualmente. Isto estaria relacionado com uma suposta maior sensibilidade que as caracterizaria. Elas seriam altamente sensíveis como as crianças e muito mais passionais do que os homens, em função de algumas marcas peculiares de sua natureza como maior delicadeza de suas fibras e irritabilidade do sistema nervoso (Jordanova, 1989; Moscucci, 1996). Segundo Peter (1980), para alguns autores, sua própria existência normal já as confundia com seres doentes e por isso eram até chamadas de "patologias ambulantes". Isto se dava em função da série de fenômenos que transformavam sua vida constantemente, como gravidez ou as "hemorragias periódicas". O curioso é que estes processos se davam dentro de uma ordem. Afinal, a própria menstruação era chamada de "regras" e indicava o estado de saúde da mulher. Mas esta ordem parecia estranha e bizarra, difícil de compreender. Por isso, as mulheres eram representadas como seres ambíguos, nos quais tudo circulava, entrava e saía. Dessa forma, seus corpos asseguram um equilíbrio perpetuamente balanceado, embora instável. Nesse modelo, "sua vida física e moral se desenvolve na mobilidade, na plasticidade, na hipersensibilidade" (Peter, 1980:83; tradução da autora).

As mulheres eram descritas na literatura médica como seres estranhos, capazes de perverter a ordem do mundo, em função de toda essa instabilidade. Ao mesmo tempo, contudo, elas eram fundamentais para a garantia dessa ordem, em virtude do seu papel como procriadoras. Era dando à luz novos seres que cumpririam a função de renovar as gerações e conservar a humanidade. Portanto, compreendê-las se tornou um imperativo para os estudiosos a partir do final do século XVIII. E em um quadro no qual importava sobretudo a razão, elas pareciam ainda mais diferentes: "são a expressão viva do que seria como um inverso da razão ou a figuração de uma humanidade ainda não tocada pela razão" (Peter, 1980:84; tradução da autora). No seu caso, os corpos ou os processos que os dominavam importariam mais do que a razão, fazendo com que se tornassem seres imprevisíveis aos olhos de uma medicina que pretendia se basear em um método racional e na busca da racionalidade dos fenômenos (Peter, 1980).

Peter (1980) toma como ponto de partida para tecer essas considerações o livro do médico francês Pierre Roussel, que em 1775 escreveu Du Système Physique et Moral de la Femme, um tratado reeditado inúmeras vezes que sintetizou as idéias do período e serviu de principal referência para a medicina durante boa parte do século XIX, inclusive no Brasil. Recorrendo a esta obra podemos aprofundar o entendimento da concepção de instabilidade feminina em cena. De acordo com Vila (1995), Roussel foi o pai da chamada "antropologia moral”, corrente da doutrina médico-filosófica em curso no fim do século XVIII e durante o XIX, que objetivava definir grupos de natureza física e essência moral distintas por meio da classificação dos vários membros da "raça humana" de acordo com idade, sexo e uma série de outras condições.

Dialogando com os trabalhos de Laqueur (2001) e Schiebinger (1987), Vila (1995) afirma que, analisando o trabalho de Roussel, é possível perceber a partir do final do século XVIII uma transformação na concepção médica sobre o ser humano que não focalizou apenas o 
sexo mas principalmente um novo sistema de sensibilidade. Segundo a autora, aplicar o esquema da oposição radical e incomensurável entre os sexos na análise da medicina do final do século XVIII é problemático, por duas razões. A primeira diz respeito ao fato de que os médicos filósofos como Roussel, quando falavam da distinção biológica entre os sexos, não estavam tratando de um órgão particular mas de todo o sistema sensível. A segunda se refere a que a nova doutrina foi desenvolvida não somente para servir a uma agenda política (dar justificativas médicas aos constrangimentos impostos às mulheres na esfera pública durante a Revolução Francesa e no Código Napoleônico), mas também para resolver certas tensões dentro do próprio campo médico (Vila, 1995).

Mais do que incorporar a noção de incomensurabilidade sexual, seria preciso, segundo Vila (1995), entender a proposta de Roussel do corpo como uma entidade sensível globalmente integrada. A questão central era recaracterizar os diversos modos pelos quais a sensibilidade funciona nos seres humanos. $\mathrm{O}$ autor propunha uma história natural da humanidade que traçasse as variações da sensibilidade na constituição normativa de cada sexo. PierreJean-Georges Cabanis, um dos mais famosos discípulos de Roussel, defendia no seu Rapposts du Physique et Moral de l'Homme, editado em 1802, que se chamasse esse tipo de medicina filosófica, que visava a explicar o papel formativo da sensibilidade no corpo e na mente, de "antropologia". Na base desse sistema estava a noção de que haveria uma sensibilidade de tipo elevado - masculina - e uma de tipo inferior ou primitivo - feminina. Dessa forma, procurava-se dar conta de entender o sistema da sensibilidade, ao mesmo tempo em que se considerava a emergente questão da diferença sexual (Vila, 1995).

O discurso de Roussel, enquanto um legítimo representante do Iluminismo francês, procurava explicar as patologias da civilização, o problema da degeneração e as possibilidades da perfectibilidade humana. Uma suposição fundamental era que antes de poder entender a natureza essencial do corpo, era preciso determinar como ele reage e interage com o mundo enquanto um ser sensível. Tanto a economia das faculdades humanas quanto a economia social eram governadas por propriedades relacionadas à sensibilidade corporal e estavam, portanto, sujeitas à intervenção médica. Os médicos filósofos pretendiam não só fazer o diagnóstico e a terapêutica do ser humano, mas também produzir um conhecimento an- tropológico e formas de intervenção na sociedade (Vila, 1995).

Na busca por definir a natureza da sensibilidade ou as variações nas funções sensíveis causadas pelo temperamento, costumes, ocupações e hábitos, o sexo era um dos fatores importantes considerados. O modelo de dois sexos diferentes, identificado por Laqueur (2001), a partir do século XVIII, era apenas uma das muitas escalas dicotômicas que os teóricos da sensibilidade criaram para identificar tipos na "raça humana". Os corpos sensíveis poderiam ser diferenciados por meio de outras oposições como camponeses versus citadinos, suíços versus parisienses, saudáveis versus patológicos, etc. A crença de que todos os corpos eram compostos da mesma matéria sensível básica permitia vê-los dentro do modelo definido por Laqueur como one-flesh model. A noção de sensibilidade monista e vitalista produzida no Iluminismo previa que todo corpo humano estaria situado em uma cadeia hierárquica. Mais do que o sexo, a sensibilidade era usada para organizar os seres humanos em superiores/inferiores, vigorosos/frágeis, refinados/grosseiros, racionais/irracionais e também suscetíveis ao Iluminismo ou não (Vila, 1995).

Roussel baseava-se em duas suposições teleológicas. A primeira diz respeito à relação entre macho e fêmea: a diferença radical é essencial para a sobrevivência da espécie e felicidade dos membros. A segunda trata da relação entre físico e moral: a sensibilidade determina o caráter físico e moral, mas de uma maneira que distingue os sexos. Assim, a doutrina de Roussel era ao mesmo tempo uma continuação da teoria da sensibilidade já existente e também uma transformação radical. Insistindo na variabilidade sexual da sensibilidade, ele resolvia um antigo problema que era a ambivalência da sensibilidade. Por um lado, ela era positiva, uma força criativa; por outro, era negativa, "um potente agente patogênico que poderia induzir fragilidade física, perversão moral e mesmo degeneração hereditária quando super desenvolvida ou mal dirigida" (Vila, 1995: 81; tradução da autora). Dessa forma, o autor constrói uma nova linha divisória entre os efeitos contraditórios da sensibilidade. Ambos os sexos, no início, dispõem dos mesmos ingredientes constitucionais básicos, principalmente a substância chamada de "tecido mucoso", responsável pela transmissão da sensibilidade. A partir da puberdade, se conforma uma redistribuição dessa substância promovendo uma distinção entre os sexos. Enquanto durante a infância meninos e meninas são semelhantes, igualmente delicados e sensíveis, com a puber- 
dade emergem as diferenças que caracterizariam a natureza única de cada sexo (Vila, 1995).

Roussel percebe a diferenciação sexual como um processo evolutivo que envolve corpo e mente e que tem na puberdade um momento crucial. Aliás, a puberdade é descrita como uma verdadeira crise médica na qual a ordem da economia animal de cada indivíduo é rearranjada. A menina experimenta uma recanalização de seus fluidos vitais para um novo centro orgânico, o útero. Entretanto, essas transformações não fazem com que ela avance muito além da constituição que tinha quando criança. Ela continua frágil, terna, retendo algo do temperamento infantil. Seus órgãos permanecem delicados e a quantidade de "tecido mucoso" aumenta e se modifica de acordo com os novos constrangimentos físicos e morais aos quais está sujeita. O menino púbere também sofre mudanças que anunciam o seu destino natural. O seu corpo torna-se mais forte, sua face, sua voz tornam-se mais masculinas, da mesma forma que o seu caráter. Tudo nele caracteriza o sexo que tem por função proteger o outro. Enquanto os homens tornam-se firmes e resistentes graças aos órgãos vigorosamente desenvolvidos e à presença de uma quantidade mínima de "tecido mucuso", as mulheres permanecem da mesma forma que eram quando crianças, ou seja, como seres delicados, vulneráveis, super sensíveis (Vila, 1995).

Nessa concepção, a natureza teria estabelecido diferenças importantes entre os sexos, tanto na sua fisiologia quanto no seu comportamento moral. Os homens seriam descritos como naturalmente resistentes aos obstáculos. As mulheres seriam capazes de ceder, mesmo involuntariamente, à pressão de múltiplos estímulos. Na verdade, o seu poder de resistência se assemelharia ao de uma criança. Há uma distribuição das qualidades físicas e morais baseada no gênero e uma impressão do gênero em sistemas e órgãos. Uma definição importante se refere à feminização do sistema nervoso e masculinização da musculatura. E mesmo dentro do sistema nervoso haveria uma distinção entre as partes frágeis e femininas e as partes fortes ou viris. O cérebro era descrito como a parte mais masculina do sistema nervoso. Nesse esquema, a inteligência, a mais nobre manifestação da sensibilidade e expressão do direito de dominação da humanidade sobre a natureza, estaria associada ao masculino. A "idade da razão" só é atingida quando a sensibilidade está tão plenamente centrada no cérebro que ela reina sobre o resto do corpo. Mas, nem todos os seres humanos seriam capazes de chegar a este estágio. No caso das mulhe- res, outros centros de sensibilidade atraíam as energias, como seria o caso do útero. Concluíase então, que homens e mulheres seriam distintos e complementares tanto na sua conformação física quanto no seu funcionamento intelectual e moral. As mulheres, mais sensitivas, sedentárias e dotadas de um cérebro mais fraco desenvolveriam algumas características próprias e teriam até algumas vantagens em relação aos homens. Estariam livres de muitos tormentos enfrentados por eles e por isso viveriam mais felizes. Teriam menos doenças crônicas e uma constituição plenamente adequada à função da maternidade (Vila, 1995).

Em Roussel, percebemos uma curiosa causalidade circular que prevê que uma dada qualidade é pré-determinada pelo sistema físico ao mesmo tempo em que o pré-determina. Tudo é concebido como se a natureza e a estrutura social colaborassem muito estreitamente. Trata-se de um determinismo naturalista que desemboca em um duplo padrão: por um lado, a sensibilidade feminina é o produto da natureza colaborando direta e harmoniosamente com a sociedade; por outro, a sensibilidade masculina, pela sua força naturalmente superior e atividade irreprimível, sempre paira em algum lugar para além dos laços societais. Enquanto a capacidade de melhorar e expandir seria uma condição normal e natural da mente masculina, não se daria o mesmo na mente feminina. A atividade do pensamento é necessária e importante para a existência da mulher, mas deve ser exercida com moderação. Se não, pelo excessivo esforço do seu sistema sensível, ela corre o risco de provocar uma modificação na natureza de seu temperamento. As mulheres são feitas para a família e não podem se envolver em estudos intensivos, como fazem os homens. Nesse modelo de complementaridade, sua "empatia natural" e sua doçura representam a base das virtudes sociais. Elas precisam, então, respeitar essa ordenação natural para preservar a sua saúde, manter a ordem social e garantir o lugar "privilegiado" que ocupam (Vila, 1995).

Segundo Vila (1995), Roussel biologizou os traços de gênero com base na sensibilidade e principalmente decretou a limitação da mulher em termos de capacidade intelectual e aperfeiçoamento mental. A teoria de Roussel, que distinguia a sensibilidade radicalmente a partir do sexo, teve grande alcance porque ele teria conseguido dar conta de associar duas visões opostas da natureza humana: a perspectiva que admitia o aperfeiçoamento e o progresso da natureza humana - expressa por exemplo em Condorcet; e a perspectiva da degene- 
ração da espécie humana - ilustrada na condenação que Rousseau faz ao progresso. Esta tensão entre dois pólos do Iluminismo não foi resolvida por Roussel. Mas, o seu modelo de sensibilidade permitiu deslocar o problema para a questão da diferença sexual. Vila afirma que embora Roussel tenha adotado uma versão modificada da posição de Condorcet, otimista, para a mente e a constituição masculinas; também assumiu a perspectiva pessimista e "fixista”, de Rousseau, para a mente e a constituição femininas.

Essa bifurcação, que torna a possibilidade do Iluminismo natural para os homens mas patológica para as mulheres, seria um resultado direto da distinção nas formas de sensibilidade que Roussel tinha proposto. Tentando salvar o modelo médico da sensibilidade, reinante naquele momento, das suas próprias contradições internas, o autor acabou por promover uma masculinização das qualidades nobres da sensibilidade e uma feminização das qualidades consideradas primitivas. Os atributos sensíveis passaram então a ser pensados como conjuntos complementares e incomensuráveis. Nesse modelo dimórfico, todos os efeitos “inferiores" da sensibilidade, como vapores, melancolia, erotomania, que antes eram admitidos também para os homens, passam a ser descritos somente nas mulheres, ou muito excepcionalmente em homens "degenerados" ou "efeminados". Enquanto os homens poderiam aspirar a um grau ilimitado de elevação mental, desde que cultivassem sua constituição corretamente, as mulheres estariam presas a um estágio menos evoluído. Segundo Vila (1995:88; tradução da autora), esse tipo de distinção ainda seria reforçado e utilizado de outras maneiras: "este cenário estava destinado a ser reiterado em termos ainda mais duros pela próxima geração de teóricos biomédicos (Cabanis, Jacques-Louis Moreau de la Sarthe, Jean-Joseph Virey entre outros) que usaram não somente diferenças sexuais mas raciais, como um pretexto para excluir da busca pela razão aqueles seres que pareciam desviar-se ou ficar aquém de certas normas morais ou fisiológicas".

IV

Os argumentos apresentados ajudam a entender que, para além da ênfase na diferença sexual, ou exatamente em função dela, a preocupação maior é com as ameaças de perturbação do seu estabelecimento e controle. Assim como Laqueur (2001) sugere, constitui-se no pensamento médico do século XIX uma verda- deira obsessão em demarcar claramente os limites entre masculino e feminino e enraizálos na natureza, na biologia. Mas, o que precisa ser acrescentado é que, embora natural ou biológica, essa diferença não está garantida. Um exemplo disso seria o fato dos médicos afirmarem que, durante a infância meninos e meninas são muito parecidos, tanto em termos de constituição física quanto de comportamento e características de temperamento. Seria na puberdade que o processo de diferenciação passaria a operar de modo a distinguir claramente os dois sexos (Ferreira, 1846). Além disso, a característica instável e maleável da matéria prima natural fica evidente no vocabulário utilizado pelos médicos, que vão falar de influências "perniciosas" (Andrade, 1839), de que as meninas arriscadamente poderiam tentar "contrariar os esforços da natureza" (Fausto, 1846), de que era preciso "administrar" a puberdade feminina (Andrade, 1839; Fausto, 1846), dirigir os impulsos (Mello, 1841) ou "ajudar a natureza" (Fausto, 1846).

A consolidação da diferença sexual depende de um processo no qual a ordem da cultura tem um papel fundamental. Se não considerarmos tal pressuposto é impossível compreender o que propõem os trabalhos médicos produzidos durante todo o século XIX. É percebendo a importância das pressões da cultura sobre o que é tido como natural que podemos entender porque as perturbações diagnósticas na época da puberdade feminina ganham tal relevância. Em especial, têm destaque aquelas vinculadas a influências como a educação, a leitura de romances, a vida nas cidades - todas de alguma forma relacionadas a um contexto de maiores possibilidades de autonomia.

Uma série de indícios permitem identificar o quanto a natureza parecia suscetível às manifestações da cultura. A própria noção de que a menstruação é o termômetro da perfectibilidade feminina (Maia, 1896), e de que a puberdade é o momento em que a menina aproxima-se da perfeição (Mello, 1841), por exemplo, já revelam que há um modelo de mulher ou de feminilidade a ser atingido. O sucesso desse empreendimento dependerá do bom governo da economia corporal da mulher. E nesse caso, a educação torna-se um grande tema de debate.

O trabalho de João de Oliveira Fausto intitulado Acerca da Menstruação, Seguida de Regras Higiênicas Relativas às Mulheres Menstruadas, apresentado à Faculdade de Medicina no ano de 1846, é um entre tantos que ilustram as concepções em jogo. O autor, preocupado em delimitar os cuidados com a formação física e mo- 
ral das meninas, focaliza especialmente a proibição de uma educação intelectual mais aprimorada. É nesse sentido que Fausto (1846) incita as mães a ajudar a natureza, contribuindo para que todos os seus esforços possam ser concentrados nos órgãos genitais. Isso significa que a excitabilidade dos outros órgãos deve ser controlada, principalmente do cérebro. A dedicação aos estudos pode fazer com que todas as energias que deveriam ser empregadas no amadurecimento do aparelho reprodutor sejam desviadas para o cérebro. Isso pode causar tanto o retardo no aparecimento da primeira menstruação, como problemas para aquelas já “regradas” que insistem em esforços mentais na época do seu ciclo. Segundo Fausto (1846: 19), "é igualmente muito importante que elas não se entreguem, durante o corrimento das regras, a trabalhos intelectuais e a estudos muito assíduos, que estabelecendo uma super excitação cerebral, determinam uma desigual divisão das forças vitais, e fazem afluir o sangue para o cérebro".

A tese de José Tavares de Mello (1841), caminha na mesma direção. No trabalho A Higiene da Mulher Durante a Puberdade e Aparecimento do Fluxo Catamenial, este autor é ainda mais enfático ao condenar a aplicação intelectual das mulheres. Justifica sua posição pela teoria do desvio das forças ao cérebro, mas também em função do lugar que a mulher ocupa na sociedade: "tristes exemplos atestam todos os dias a inutilidade, e até o perigo de obrigar as meninas à cultura das ciências, e demonstram os inconvenientes de uma aplicação muito sustentada, e a perniciosa influência que ela exerce sobre a saúde. A excitação prolongada do cérebro não se limita só a fazer dele o centro exclusivo de ações e movimentos, enfraquecendo a energia dos outros órgãos; mas o força também a tornar-se a sede de uma suscetibilidade, que ocasiona cefalgias, doenças nervosas, e outras muitas afecções, que envenenam os mais belos dias da existência das mulheres ... A espécie de império, que exercem na sociedade, exige que elas não sejam ignorantes; porém não lhes é devido o mesmo grau de instrução dos homens, cujos destinos partilham e embelezam. O estudo moderado das artes de recreação é o único que lhes convém; porém somente como meio de adoçar as tristezas, suavizar o aborrecimento da solidão, lançar sobre o curso de sua vida doces $e$ agradáveis distrações, de variar enfim os prazeres distraindo-as em seus trabalhos" (Mello, 1841:15).

Como podemos ver, a educação poderia se constituir em uma influência cultural extremamente perturbadora, prejudicando todos os es- forços que a natureza fazia no sentido de garantir o bom desenvolvimento da capacidade reprodutiva feminina. Fica evidente também que está em jogo nesses discursos o império da noção de que a primeira e talvez a única função da mulher é a procriação e que, portanto, tudo deve ser feito no sentido de que seja realizada a contento. É bom lembrar que é no decorrer do século XIX que aparecem com mais força as reivindicações em torno de educação, trabalho e uma série de outros direitos que tornavam evidente a demanda por mais autonomia por parte das mulheres. Isso colocava em cena a discussão sobre como as mudanças nos comportamentos das mulheres representariam transformações para a sociedade como um todo. Entrava em foco, então, um amplo debate acerca do que era considerado natural ou social no comportamento de homens e, sobretudo, de mulheres. No caso destas últimas, tentava-se, por um lado, advogar que poderiam preencher outros papéis além da maternidade. Por outro, buscava-se provar que seu corpo era de tal ordem pré-determinado para a procriação que isto tornava as mulheres incapazes para outras tarefas.

Procurei mostrar como a produção médica em torno dos temas da puberdade e da menstruação revelam uma série de discussões em torno da questão da diferença sexual. Tal como demonstrado pelos estudos que tratam do tema e ilustrado pelos trabalhos médicos citados, percebe-se a produção de um discurso que se caracteriza por descrever as diferenças entre os sexos, sobretudo por meio da análise das supostas especificidades femininas. As características biológicas observadas nas mulheres correspondem, do ponto de vista dos médicos, a uma clara delimitação das suas capacidades físicas e mentais e, portanto, dos papéis que podem assumir na sociedade. Contudo, além dessa ênfase na diferença calcada em argumentos biológicos associados a demandas culturais, tentei trazer elementos que permitem complexificar o debate em torno da diferença.

O mais importante a ser destacado é o fato de que a imensa preocupação em descrever pormenorizadamente aquilo que distingue homens e mulheres, se constitui exatamente em função da percepção de que as fronteiras entre os sexos não eram estanques. Era a admissão de que os limites não estavam garantidos que chamava a atenção dos médicos. Sem dúvida, eles operavam com uma concepção na qual a natureza havia provido as diferenças básicas entre os sexos. Mas, essas diferenças eram operacionalizadas e cristalizadas ao longo da vida 
de homens e mulheres. E a puberdade era um momento em que esta operacionalização ganhava um impulso mais forte. Embora naturais ou biológicas, as diferenças não estavam garantidas. Dependiam de uma boa administração dos fatores internos e externos que poderiam intervir no processo. As influências do meio, as ingerências da cultura, poderiam ser responsáveis pela boa finalização do percurso ou pela perversão dos caminhos traçados pela natureza. Nesse sentido, tratar do predomínio da diferença sexual nos textos médicos do século XIX, é tratar também de uma grande preocupação com a instabilidade dos sexos. Era porque as fronteiras entre um e outro sexo e o processo de estabelecimento da diferença eram instáveis, que tanto se enfatizava as características que idealmente distinguiriam homens e mulheres no plano da natureza e da sociedade.

Para além dessa primeira constatação em torno da instabilidade da diferença sexual, é preciso também reconhecer que a instabilidade opera de maneira distinta na forma pela qual são considerados homens e mulheres. Como vimos por meio da análise do trabalho de $\mathrm{P}$. Roussel (Vila, 1995), elabora-se a partir do final do século XVIII uma corrente de pensamento que percebe a mulher como dotada de um tipo de sensibilidade particular, comparativamente ao homem. Em virtude de uma constituição mais fraca e delicada, ela seria muito mais vulnerável às influências perigosas que poderiam alterar a sua economia corporal e mental. A educação, por exemplo, naturalmente difícil pela sua pouca capacidade intelectual, especialmente durante a puberdade, poderia prejudicar o bom desenvolvimento dos órgãos reprodutivos e, conseqüentemente, o desempenho futuro do papel de mãe. Caberia então um cuidado muito mais acentuado com o amadu- recimento das meninas. Os médicos se propunham a identificar os perigos e os prejuízos de hábitos e comportamentos que pudessem desvirtuar a ordem natural.

Em um período onde estabelecer os limites claros entre os gêneros parecia imperioso, a concepção de uma instabilidade específica às mulheres atraía ainda mais os médicos. Se em um plano a concepção da instabilidade da diferença sexual era ameaçadora, em outro, era a percepção de uma maior vulnerabilidade das mulheres que gerava demandas por um modelo particular de entendimento da relação entre natureza e cultura. Tornava-se uma questão fundamental definir exatamente o que pertencia a cada um dos domínios. Mas isto não servia simplesmente para diagnosticar aquilo que supostamente seria imutável - na natureza ou passível de transformação - na cultura. A relação entre os dois níveis era extremamente complexa e fluida. Ingerências vindas dos dois lados caracterizavam os esquemas imaginados pelos médicos.

Tudo isso nos remete para a importância da concepção de natureza e cultura na sociedade ocidental como um operador que responde às demandas sociais em cada contexto. A forma particular de definir a oposição natureza/cultura gestada com o Iluminismo, tem sido fundamental para embasar os modelos de relações de gênero construídos desde então e que são traduzidos pelos textos médicos. Perceber que o conteúdo e as propriedades atribuídas ao mundo natural ou cultural variam significativamente e que a própria existência da dicotomia não é universal, contribui para uma compreensão mais abrangente da produção científica da qual, afinal de contas, somos herdeiros, e também dos modelos de gênero e de sexo que esta produção ajudou a elaborar. 


\section{Referências}

ANDRADE, J. C., 1839. A Puberdade na Mulher. Tese. Rio de Janeiro: Faculdade de Medicina do Rio de Janeiro.

BARBOSA, P. L., 1891. Desordens Catameniais. Tese. Rio de Janeiro: Faculdade de Medicina do Rio de Janeiro.

BULLOUGH, V. \& VOGHT, M., 1973. Women, menstruation, and nineteenth-century medicine. Bulletin of the History of Medicine, 47:66-82.

FAUSTO, J. O., 1846. Acerca da Menstruação, Seguida de Regras Higiênicas Relativas às Mulheres Menstruadas. Tese. Rio de Janeiro: Faculdade de Medicina do Rio de Janeiro.

FERREIRA, J. S., 1846. A Reprodução. Tese. Rio de Janeiro: Faculdade de Medicina do Rio de Janeiro.

GAY, P., 1984. Education of the Senses. New York/Oxford: Oxford University Press.

JORDANOVA, L., 1989. Sexual Visions, Images of Gender in Science and Medicine Between the Eighteenth and Twentieth Centuries. London: Harvester Wheatsheaf.

KENT, S. K., 1990. Sex and Suffrage in Britain (18601914). London: Routledge.

LAQUEUR, T., 1987. Orgasm, generation, and the politics of reproduction biology. In: Making of the Modern Body (C. Gallagher, ed.), pp. 1-41, Berkeley: University of California Press.

LAQUEUR, T., 2001. Inventando o Sexo: Corpo e Gênero dos Gregos a Freud. Rio de Janeiro: Relume Dumará.

MAIA, V. J., 1896. A Menstruação na Etiologia das Nevroses e Psicoses. Tese. Rio de Janeiro: Faculdade de Medicina do Rio de Janeiro.

MARTENSEN, R., 1998. A transformação de Eva: Os corpos das mulheres, medicina e cultura no início da Inglaterra moderna. In: Conhecimento Sexual, Ciência Sexual: A História das Atitudes em Relação à Sexualidade (R. Porter \& M. Teich, org.), pp. 133-164, São Paulo: Editora UNESP.
MATUS, J. L., 1995. Unstable Bodies: Victorian Representations of Sexuality and Maternity. Manchester: Manchester University Press.

MELlO, J. T., 1841. A Higiene da Mulher Durante a Puberdade e Aparecimento Periódico do Fluxo Catamenial. Tese. Rio de Janeiro: Faculdade de Medicina do Rio de Janeiro.

MOSCUCCI, O., 1996. The Science of Woman: Gynaecology and Gender in England (1800-1929). Cambridge: Cambridge University Press.

PETER, J.-P., 1980. Les médecins e les femmes. In: Misérable et Glorieuse. La Femme du XIXème Siècle (J.-P. Aron, ed.), pp. 79-97, Paris: Fayard.

RUSSETT, C. E., 1995. Sexual Science. The Victorian Construction of Womanhood. Cambridge: Harvard University Press.

SCHIEBINGER, L., 1987. Skeletons in the closet: The first illustrations of the female skeleton in eighteenth-century anatomy. In: Making of the Modern Body (C. Gallagher, ed.), pp. 42-82, Berkeley: University of California Press.

STEINBRÜGGE, L., 1995. The Moral Sex. Women's Nature in the French Enlightenment. Oxford: Oxford University Press.

VERTINSKY, P., 1990. The Eternally Wounded Woman: Women, Doctors and Exercise in the Late Nineteenth-Century. Manchester: Manchester University Press.

VILA, A. C., 1995. Sex and sensibility: Pierre Roussel's système physique et moral de la femme. Representations, 52:76-93.

Recebido em 7 de agosto de 2003

Aprovado em 1 de setembro de 2003 